\title{
B

SISTEMA RADICULAR DO MORANGUEIRO (FRAGARIA HIBRIDOS), EM DUAS FASES DO CICLO VEGETATIVO ( $\left.{ }^{(}\right)$

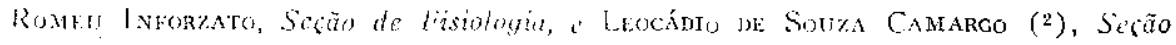

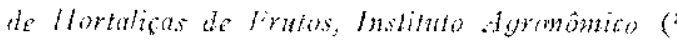

\section{SINOPSE}

São amesentados os resultatios do estudo do desenvolvimento do sistemia radicular do morangueiro (Fragaria híloridos), variedade Campinas IAC-2712, con 105 a 201 dias de plantio das mudas, en Latossolo Vermelho Amarelo série Barão, do município de Campinas.

() mo:angueiro apresentou, a $5 \mathrm{~cm}$ de profundidade do solo, $73 \%$ e $90 \%$ em peso de suas raízes, respectivamente nas idades de 105 e 201 dias. A profundidade máxima atingida pelas raízes nats duas idlacles estudadas foi de $55 \mathrm{~cm}$.

\section{1 - INTRODUÇÃO}

O cultivo do morangueiro (Fragaria híbridos) no Estado de São Paulo já assume papel econômico de relevância. A sua produção em 1969 foi estimada em 6760 toneladas, obtidas em área de 340 hectares.

Na quase totalidade das plantações do Estado de São Paulo a variedade em cultivo é a Campinas IAC-2712, que foi criada na Seção de Hortaliças de Frutos em 1955, pelo cruzamento entre as

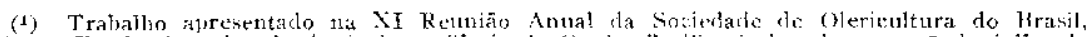
realizada ra Jiscolit superior he Apricultura "Luiz de Oneitoz", l'iracicaba, de 11 a 17 de jultho de

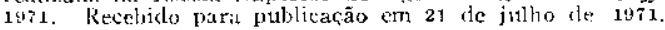

(2) Cum bolsa de surplementasĩo do $\left(\mathrm{x}^{2}\right)^{\prime}$.

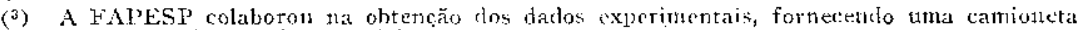
latit transporte: de técnicos e de materiais. 
variedades Donner I-2183 e Tahoe I-2185, ambas procedentes da Universidade da Califórnia, Estados Unidos (1-3).

Natividade (5) afirma que o estudo das partes aérea e subterrânea do morangueiro mostra que o desenvolvimento desta última é sobretudo ativo logo que termina a frutificação. Esse mesmo autor escreve que, ao contrário de tantos outros vegetais em que a raiz principal incessantemente se ramifica e aprofunda. explorando novos volumes de terra, o sistema radicular do morangueiro é renovado pelo aparecimento de raízes sobre o caule, que é um rizoma, em um plano acima das já existentes. Graças a essa forma de renovação, as raízes são pouco profundas.

Nelson e Wilhem (6), estudando as variedades do morangueiro "Lassen" e "Shasta" (Fragaria híbridos) em solo arenoso, desinfetado, verificaram que as raízes atingem até $60 \mathrm{~cm}$ de profundidade, com muitas ramificações até essa camada do solo. As raízes principais são grandes e perenes, têm a função de órgãos de reserva e contribuem também ativamente na absorção de alimentos pelo contínuo crescimento e pela produção sucessiva de novas radicelas. Estas, produzidas pelas raízes principais ou suas ramificações, têm curta duraçāo. A vida saudável do morangueiro, no que diz respeito às suas raízes, depende da contínua produção de novas raízes principais do caule e da possibilidade de essas raízes produzirem novos tecidos, o que assegura existência duradoura à planta.

Neste trabalho são apresentados os resultados do estudo do desenvolvimento do sistema radicular do morangueiro aos $105 \mathrm{e}$ 201 dias do ciclo vegetativo, quando em condições normais de cultivo.

\section{2 - MATERIAIS E MÉTODOS}

O estudo foi realizado no Centro Experimental de Campinas, em Latossolo Vermelho Amarelo série Barão.

A variedade de morangueiro usada foi a Campinas IAC-2712, da qual foram plantadas, em 24 de abril de 1970, 180 mudas, no 
espaçamento de $0,30 \mathrm{~m} \times 0,30 \mathrm{~m}$. As irrigações por aspersão (em forma de esguicho) foram feitas após o plantio, cada dois ou três dias. Após o plantio, o solo entre as plantas foi coberto com casca de arroz.

A amostra de solo retirada do local do experimento foi analisada pela Seção de Fertilidade do Solo e revelou os seguintes resultados:

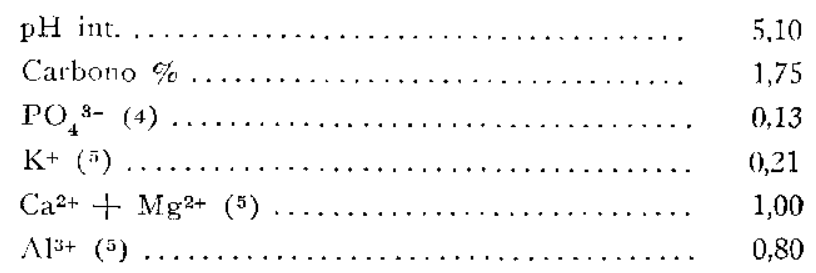

De posse desses dados, em 12 de março de 1970 foi aplicada a seguinte adubação por metro quadrado: superfosfato simples - $400 \mathrm{~g}$; cloreto de potássio - $40 \mathrm{~g}$; sulfato de amônio $-20 \mathrm{~g}$; e em cobertura, a cada 15 dias, a contar da data do plantio, $20 \mathrm{~g}$ de sulfato de amônio por metro quadrado, até fins de novembro.

O controle de pulgões e ácaros foi feito com pulverizações de Phosdrin a $0,2 \%$. Os ácaros foram também combatidos com pulverizações de Tedion $\mathrm{V}-18$ a $0,2 \%$. A proteção contra a mancha-das-folhas foi feita com pulverizações de Dithane M-45 a $0,2 \%$.

Para evitar que as raízes das ervas más interferissem no desenvolvimento do morangueiro, a plantação foi mantida no limpo.

O estudo da distribuição do sistema radicular dessa planta foi feito aos 105 e 201 dias após o plantio das mudas, época de maior produção e fase final de colheita, respectivamente. Empregou-se a técnica utilizada por Franco e Inforzato (4) no estudo do sistema radicular do cafeeiro. 
Para o estudo do desenvolvimento do sitema radicular, nas duas épocas foram selecionadas sete plantas sadias e uniformes, espaçadas de $0,30 \mathrm{~m}$ entre si, na linha do canteiro. Determinaram-se a altura, o diâmetro e o número de folhas de cada planta, após o que foi cortada a parte aérea, pesando-se as folhas e os frutos. Feito isso, abriu-se uma valeta no sentido longitudinal às linhas de plantas, para a retirada de blocos de terra com raízes. Para as duas idades consideradas foram retiradas seis camadas de blocos, cada camada contendo sete blocos. As dimensōes dos blocos foram as seguintes: três camadas de blocos de $5 \times 30 \mathrm{x}$ $30 \mathrm{~cm}$, duas camadas de blocos de $10 \times 30 \times 30 \mathrm{~cm}$ e uma camada de blocos de $20 \times 30 \times 30 \mathrm{~cm}$.

Após a extração, os blocos de terra foram levados a um galpão, onde as raízes foram separadas por peneiramento; depois dessa prática, as raízes foram lavadas, secas ao ar e pesadas.

\section{3 - RESULTADOS}

No quadro 1 constam os dados fenotípicos das plantas, determinados nas idades de 105 e 201 dias após o plantio, e no quadro 2 as quantidades em peso e porcentuais das raízes das plantas nessas mesmas idades, nas diferentes camadas do solo dos canteiros.

\section{4 - CONCLUSÕES}

a) O morangueiro apresentou nos cinco primeiros centímetros do solo, respectivamente nas idades de 105 e 201 dias, cerca de $73 \%$ e $90 \%$ em peso de suas raízes. Verificou-se aumento de raízes aos 201 dias somente nos 5 primeiros centímetros de profundidade do solo; a partir dessa camada, até $55 \mathrm{~cm}$ de profundidade o sistema radicular diminuiu progressivamente, nas duas idades consideradas.

b) Quanto à profundidade máxima atingida pelas raízes, não houve diferença entre essas idades, pois em ambas foi de $55 \mathrm{~cm}$. 
Quadro 1. - Darlos fenotipicos de moranguciros var. IAC-2712, cultivados em Latossolo Vermelho Amarelo séric Barão, no Contro Fxperimental de Canzpinas, com 105 c 201 dias de idade, c utilizados para o estudo do sistema rarlicular

\begin{tabular}{|c|c|c|c|c|c|}
\hline Planta & Altura & $\begin{array}{l}\text { Diâmetro } \\
\text { da } \\
\text { touccira }\end{array}$ & Folhas & $\begin{array}{l}\text { Peso } \\
\text { das } \\
\text { folfas }\end{array}$ & $\begin{array}{c}\text { Peso } \\
\text { dos } \\
\text { frutos }\end{array}$ \\
\hline 105 dias & $c m$ & $\mathrm{Cm}$ & $n 0^{0}$ & $g$ & $g$ \\
\hline $1 \ldots \ldots \ldots \ldots$ & 14 & 37 & 18 & 56 & 32 \\
\hline $2 \ldots \ldots \ldots \ldots$ & 13 & 34 & 14 & 44 & 20 \\
\hline $3 \ldots \ldots \ldots$ & 14 & 33 & 17 & 43 & 24 \\
\hline $4 \ldots \ldots \ldots \ldots$ & 12 & 27 & 9 & 23 & 15 \\
\hline $5 \ldots \ldots \ldots \ldots$ & 13 & 32 & 10 & 23 & 8 \\
\hline $6 \ldots \ldots \ldots \ldots$ & 12 & 30 & 12 & 27 & 18 \\
\hline $7 \ldots \ldots \ldots \ldots$ & 13 & 33 & 20 & 49 & 4 \\
\hline Média $\ldots . .$. & $1,3,0$ & 32,3 & 14,3 & 37,8 & 17,2 \\
\hline 201 dias & & & & & \\
\hline $8 \ldots \ldots \ldots \ldots$ & 11 & 21 & 22 & 30 & 0 \\
\hline $9 \ldots \ldots \ldots \ldots$ & 14 & 25 & 22 & 36 & 0 \\
\hline $10 \ldots \ldots \ldots \ldots$ & 18 & 27 & 30 & 44 & 9 \\
\hline $11 \ldots \ldots \ldots \ldots$ & 12 & 28 & 15 & 19 & 8 \\
\hline $12 \ldots \ldots \ldots \ldots$ & 11 & 22 & 11 & 15 & 0 \\
\hline $13 \ldots \ldots \ldots$ & 13 & 25 & 10 & 15 & 5 \\
\hline $14 \ldots \ldots \ldots \ldots$ & 12 & 22 & 21 & 23 & 0 \\
\hline Mérlia $\quad \ldots . .$. & 13,0 & 24,2 & 18,7 & 26,0 & 3,1 \\
\hline
\end{tabular}

c) Nas condições estudadas, o sistema radicular do morangueiro pode ser considerado bastante raso, o que sugere que a cultura deve ser mantida sempre limpa e protegida por cobertura morta, a fim de manter úmida a camada superficial do solo e evitar que as ervas más concorram aos nutrientes e à água. 


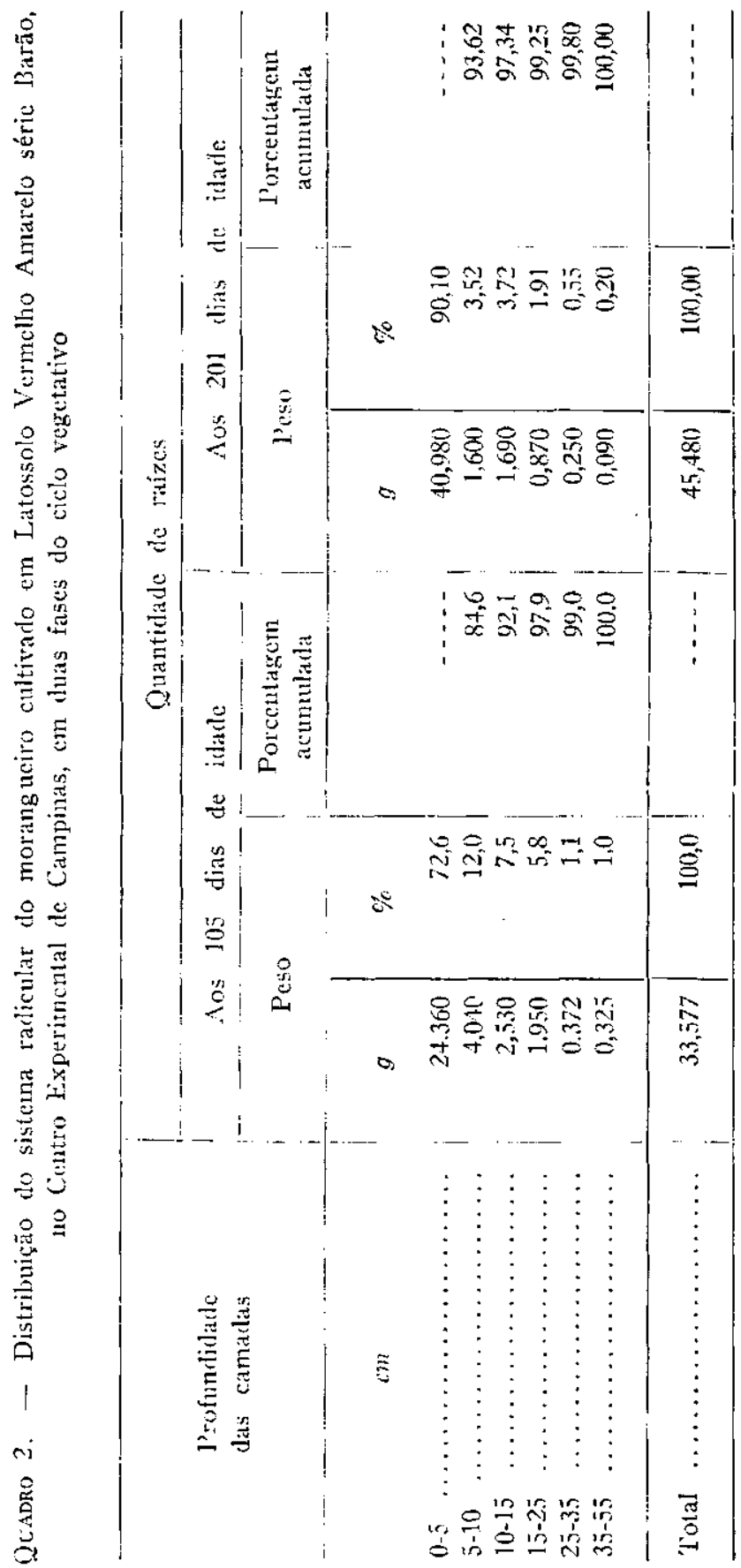


DISTRIRETION OF THE ROOT SYSTEM OF STRAWBERRY PLANTS

\section{SUMMARY}

A study of root distribution of strawberry plants was made in a Red Yellow Latosulic soil of the «Harão» series.

On a weight basis, $73 \%$ and $90 \%$ of the roots were found in the upper $5 \mathrm{~cm}$ layer, respectively at 105 and 201 days after transplanting. The maximum depth reached by the root system was $55 \mathrm{~cm}$.

\section{LITERATURA CITADA}

1. CAluARGo, L. S. Instruções para a cultura do morangteiro. Campinas, Instituto Agronômico, 1966. 19p. (Boletinn 29)

2. - Novas variedades de morangrnciro para o Estado de São Panlo. Piracicaba, Escola Superior de Agricultura «Luiz de Queiroz», 1960. 48fls. (Tese de doutoranento) (Resumida en Agronômico 13(1/2):30-32. 1961)

3. - ALVES, S.; SCARANARI, IJ, \& ABRAMIDES, E. Novos cultivares de morangueiro para a regiño do «Alto Piracicaba» no planalto paulista. Bragantia 27:117-133, 1968.

4. FRANCO, C. M. \& TNFORZATO. R. O sistema radicular do cafeeiro nos principais tipos de solo do Estado de São Paulo. Bragantia 6:443-478, 1946.

5. NATIVIDADE, J. V. Cultura dos moranguciros. Alcobaça, Of. José de Oliveira Jr., 1940. 1351).

6. NELSON, P. E. \& WILHEM, S. Some anatomic aspects of the strawberry root. ILilgardia 26:631-642, 1957. 